\title{
Standing on the Edge: How School Leaders Apply Restorative Practices in Response to Cyberbullying and Online Aggression
}

\author{
Laurie Corrigan, Lorayne Robertson \\ University of Ontario Institute of Technology, Canada
}

\begin{abstract}
This paper summarizes findings about restorative practices as one aspect of a research study examining vice-principals' responses to harmful cyber events such as cyberbullying and online aggression. It also considers the school's moral and legislated role in responding to these events. It is theorized that these negative online interactions occur as a result of a lack of social regulation, social presence, and empathy. Three theories are considered in connection to cyber conflict and cyberbullying: Tompkins' affect theory; Braithwaite's re-integrative shame theory; and Rettie's social presence theory. The first two are key restorative practices theories while the third considers social presence in online learning environments. Findings indicate that schools are a nexus for online events where the intersection of these theories is evidenced in practice. Based on these findings, recommendations include deliberate consideration for introducing elements of social presence, online regulation, community building, and empathy before and responding to cyber events.
\end{abstract}

\section{Introduction}

Social media, including Vine, Twitter, Facebook, texting and chats, has altered conventional social interaction for many Canadian adolescents. The portable quality of technology in laptops, tablets, and cell phones provides immediacy of communication, but it also means that intimate and potentially risky communication can take place away from supervision. For example, adolescents can communicate from any room rather than only in a regulated environment such as the kitchen or family room where the influence of parental supervision is more likely to occur.

Cyberbullying is a social phenomenon which causes harm to persons, including vulnerable adolescents, who are participating in the unregulated online environment. Current research literature suggests that cyberbullying is an international phenomenon affecting adolescents [3], [5], [9], [10], [14]. While cyberbullying appears to be increasing in scope, Cassidy, Faucher, and Jackson suggest it is still a newly-emerging phenomenon [6]. There is much to be learned and shared about cyber misbehaviour particularly as it relates to social regulation through social presence.

This study considers how this lack of regulatory influence (historically exercised at home or at school) is connected to cyber misconduct. These cyber events, occurring 24/7 inside and outside the school community, happen in most cases without the presence of face-to-face communication, an interaction which is thought to help regulate behaviour through social presence. This study also examines how social presence and regulation are being re-established now in some school communities by secondary school vice principals who use restorative practices to respond to incidents of cyberbullying and online aggression.

\section{Schools' legislated role}

The province of Ontario, which has the largest population in Canada, has implemented various safe schools policies over the last fifteen years. For example, an earlier policy, the Safe Schools Act, 2000 [8] advocated a zero tolerance approach to school discipline. Zero tolerance generally features an automatic, pre-determined response to certain transgressions without contextual consideration. While zero tolerance responses afford the political perception of "solving the problem", they can also have negative consequences because they do not necessarily consider the needs of the offenders and the victims. As a result, these zero tolerance policies were viewed as a punitive set of measures by the Ontario Human Rights Commission four years later [19]. The revised Safe Schools Policy set by the province in 2006 [22] was seen to offer more progressive and restorative approaches to school discipline to respond to school-based incidents of conflict and harm.

Even though research suggests that adolescents spend in excess of seven hours a day using social 
media [23], they still spend a considerable portion of their day in school and within school-related activities. Given the prevalence of cyberbullying and the school's expected role and purpose in response to it [10], it has been suggested by Grossi and dos Santos [9] that restorative practices, a means of repairing harm done to others, has the potential to effectively respond to incidents of bullying and cyberbullying.

Presently, in Ontario, Bill 13 the Accepting Schools Act, 2012 [12], expands the definition of bullying to include online bullying or cyber-bullying and requires schools to address all incidents of harassment, bullying, and discrimination which come to their attention. Interventions continue to include suspension and expulsion but also other approaches. All of the aforementioned policies have been deployed in Ontario with the aim of providing safer schools, but the introduction of online offenses in Bill 13 establishes the school as a nexus for the revelation of cyber events and their consequences. Given these recent developments in legislation and the impact of bullying and cyberbullying on students and school culture [14], an emerging research question was considered: What happens when secondary school administrators use restorative practices to respond to student incidents of online aggression and cyberbullying?

While other studies examining the efficacy of restorative practices have been undertaken $[3,5]$ including those that occur from a lack of social regulation, little evidence exists about the effectiveness of restorative practices in response to cyberbullying and aggression, two cyber phenomena affecting adolescents globally.

Restorative practices require the voluntary participation of both the victim and the offender and these practices are believed to increase personal accountability because they bring both parties together. [3,5,9] Similarly, a lack of face-to-face interaction, or lack of personal accountability through presence, is considered to be an underlying cause of cyber behaviour [14].

Cyberbullying and online aggression continue to affect adolescent populations with negative interaction that is compounded by the use of technologies that include social media [16]. Research indicates $[23,24]$ that restorative practices, a means of repairing harm done to others in community, in conditions that include the opportunity for face-toface communication, may have some potential to effectively respond to cyberbullying in an environment that has a dearth of social presence.

Because cyber bullying and cyber conflict are two phenomena affecting adolescents globally, and if the school has a legislated expectation to intervene, restorative practices in schools which afford participants an opportunity to make things right have the potential to respond to cyberbullying and other cyber conflicts including online aggression.

The legal system not only influences the general public, but it also influences education. Restorative justice attempts to address limitations in the justice system that leave victims, offenders, and law professionals unsatisfied. The Safe Schools Action Team of the Ontario Ministry of Education [22] now requires that safe schools policies include restorative practices as part of a series of preventive and responsive strategies.

An examination of the origins of restorative justice in the legal system is helpful in understanding how these principles are being adapted for schools [25].

\subsection{Origins - Restorative justice}

Restorative justice and restorative practices are two terms that appear to be used synonymously in schools and other institutions. However, an examination of literature about these approaches reveals how they can be distinguished from each other and from punitive measures.

For the victim, Zehr [25] argues that punitive measures do not necessarily afford the opportunity for truth telling, information dissemination, empowerment, or vindication to take place. For the offender, the sanctions or punitive measures do not necessarily afford the opportunity for responsibility taking or empathy building to take place.

Zehr [25] contends that restorative justice affords those who are involved in the offense, including the victim and the offender, the opportunity to repair the harm done after an event of wrongdoing. Restorative justice does not, however involve a process of mediation, forgiveness, and reconciliation. It is not a program, nor is it designed to reduce repeat offenses [25].

Restorative justice is a process that involves, to the greatest extent possible, those who have a stake in a specific offense to collectively identify and address harms, needs, and obligations, in order to heal and put things as right as possible. [25]

While Wachtel maintains that restorative practice is connected to the Victim Offender Reconciliation Program that began in the US and Canada in the 1970's and 1980's [24], Zehr indicates that restorative justice has its origins in the Mennonite populations in Ontario, Canada and Indiana, USA [25]. He concludes that it has also evolved into a variety of cultural and religious traditions drawing significantly on the rituals of the aboriginal communities of North America and New Zealand. 
Restorative justice, however, is not a panacea, and it is not an alternative to prison, nor is it necessarily the opposite of retribution [25].

\subsection{Restorative Practices}

While the legal system establishes consequences that are punitive and authoritarian [25], restorative principles establish the offense as a violation against community and the relationships therein. This violation evolves a sense of responsibility which then becomes the necessary obligation to make things right [25]. In both retributive and restorative justice, wrongdoing is acknowledged, but the focus of the acknowledgement in restorative practices is in the form of harms and needs and not vindication [24].

\subsection{Applications to school}

According to Wachtel [24], restorative justice practices which are adapted in schools are referred to as restorative practices. While core approaches often include an encounter that includes all of the stakeholders - the victim, the offender, and community members - it can include representatives or surrogates and can also include letters or videos. School gatherings are led by school leaders who facilitate settlements that are not imposed, that are voluntary, and that acknowledge responsibility. If these criteria are not met, the meeting does not proceed [24].

Wachtel maintains that an encounter is necessary among the victim, the offender, and those members of the community who are affected in order to repair the harm done. He identifies a number of interventions that can be used to respond to wrongdoing. From restorative statements that are intended to establish empathy and increase communication, to informal and formal conferences, restorative practices follow a continuum [24].

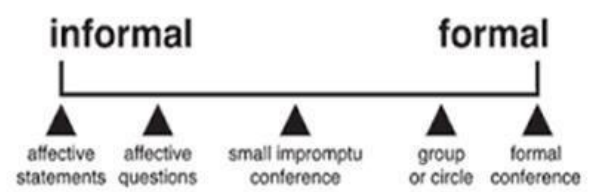

Figure 1. Restorative Practices Continuum (Wachtel, 2013)

Restorative practices also include a number of questions [24]:

When things go wrong...

1. What happened?

2. What were you thinking of at the time?

3. What have you thought about since?
4. Who has been affected by what you have done? In what way?

5. What do you need to do to make things right?

When someone has been harmed...

1. What did you think when you realized what had happened?

2. What impact has the incident had on you and others?

3. What has been hardest thing for you?

4. What do you think needs to happen to make things right?

Currently, researchers [15, 16] are examining approaches and practices used by organizations, schools, and religious institutions. While schools may adopt restorative practices, [16] fundamental differences between judicial and educational contexts exist which cannot be overlooked. In law, a relationship between the victim and the offender is not necessarily present but in schools, relationships are fundamental, even after harm has been done. This is why the offense is seen as a violation of community and relationships.

McCluskey et al., further contend that, while there has been a strong base of support for restorative practices in schools, there has not been a great deal of rigorous research conducted in this area [16]. They also question the rehabilitative aspect of restorative justice as irrelevant to schools (which are not penal institutions), but they do conclude that whole-school restorative approaches that include student-to-student and staff -to -staff conferences are of promise as restoring elements in that environment [16].

In distinguishing the two approaches, Wachtel [24] suggests that restorative justice is a reactive process which takes place after wrongdoing has occurred. In comparison, restorative practices are a range of practices in a continuum [24] and these practices can be used also to precede wrongdoing and to prevent harm. McCold and Wachtel [17] for example, contend that the use of restorative practices can enhance the overall level of civility in society. The use of these restorative practices can reinforce (and model) appropriate social interaction. As such, these practices can be used to handle disputes.

McCold and Wachtel [17] describe four broad policy models for dealing with behaviours. A punitive policy model has high control but low personal support. It is authoritarian and stigmatizing. A neglectful model has low control and low support. A permissive model is very supportive but has low control. A restorative model, however, is described as having high collaboration and high support. They contend that restorative approaches have "a history of success in families, communities, organizations and international relations" [17], p. 123. This premise is 
reflected in Figure 2: Wachtel's (2013) social discipline window [24].

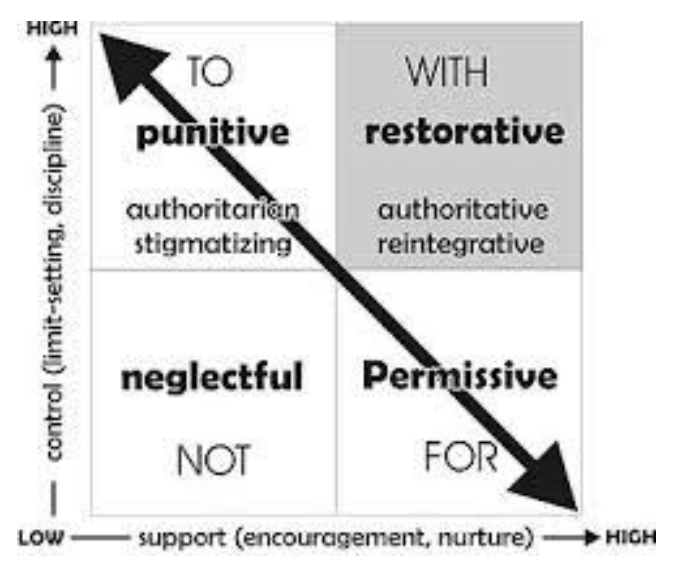

Figure 2. Social Discipline Window (Wachtel, 2013)

\section{Theoretical Perspectives}

Tomkin's [21] who pioneered affect theory, contends that responses to events are biological and innately occurring and take place through face-toface communication. Cyberbullying, online aggression, and online conflict take place without the stabilizing effects of this face-to-face communication. Rettie [20] theorizes that social presence is the judgement of one online participant's sense of the other, a perspective that may or may not be accurate in online environments due to geographic distance or chronological distance. In restorative practices, these elements of face-to-face social presence and affect are re-integrated into the relationship. Braithwaite [4], building on Nathanson's shame theory [as cited in 24], theorizes that re-integrative shame is a powerful means of getting people to do the right thing, maintain community and, in the process also maintain their place in it. An exploration of the interactions of these relevant theories at the nexus of the school helps to shed light on why restorative practices may be a viable means of responding to cyber conflict and bullying.

\subsection{Social presence theory}

In the context of online teaching, Rettie [20] refers to social presence as judging the other participant's perception, and that perception includes the immediacy and intimate quality of online communication toward building community. We approach social presence building as a missing element in student-to-student cyber events which are harmful. For some students, social media then can at least evoke the vestiges of community [11], but without the regulation of social presence, it is a community that can create great harm to its members

According to recent research, students who spend time together with limited access to technology are better able to interpret the emotions of other adolescents through non-verbal visual cues [23].

Aragon [2] considers different aspects when defining social presence in the context of online learning and online courses. He sees that social presence includes both the ability of the sender and receiver to be to be perceived as persons to each other [2].

We contend that this type of social presence or awareness of each other as people has, in the past, most commonly been achieved through face-to-face communication. This face-to-face presence can help to regulate social interaction or social conduct, but it can be argued that this connection between persons is more difficult to achieve in online environments such as social media.

This quality of community, as evidenced in student access to online communities 24/7, means that students' ideas of community might be as distant as being one of 100,000 followers or as immediate as instant messaging. Students may use online communities either negatively or positively. This online experience, as instantly gratifying yet potentially problematic as it may be, can also serve as a learning experience. Inevitably, social presence will comfortably or uncomfortably increase when students walk through the halls of the school and into their classrooms and meet online peers in person.

Social capital is another element that makes up a community. If social capital is the glue that makes up students' private and public lives, then it also affords an opportunity to establish a regulatory influence that comes from positive social relationships [18]. Morrison [18] explains how restorative practices can restore the balance of social capital in school communities and among students in particular. The cell phone itself represents tremendous social capital insofar as the student is attached to it 24/7 and to a myriad of contacts, which can be negative and positive. This connection serves as a virtually unregulated frontier in which to further cultivate social capital since the adolescent is connected to family, friends, and those who constitute neither. It is also possible that restorative practices may increase social capital in online and cyber environments.

\subsection{Affect theory of restorative practices}

Tomkins theory of affect learning considers the innate reasons why people behave in the ways they do. He identifies nine affects, three positive and six 
negative, which represent a student's primary motivational system. Of these nine affects, two are positive and include interest-excitement and enjoyment or joy. One is neutral and is identified as surprise or startle. Six are negative and include angerrage, fear-terror, distress-anguish, disgust, dissmell (shunning) and shame-humiliation. Typically, both negative and positive emotions, evidenced through the visages of students, are more evident in face-toface communication. From thinking, to judging, to acting, students then are hardwired to look at the face of the other and understand innately how someone else, stranger or friend, is feeling [13].

Online communication and the potentially anonymous quality of social media do not represent ideal opportunities to increase this affect because face-to-face communication does not typically occur. Research on remediating loss of visual cues indicates that replacing screen time with face-to-face communication can help students to see the other person and determine an appropriate response [23]. Increasing positive affect can happen through the use of a number of restorative practice approaches used by school administrators which include restorative conferences, questions, and restorative circles because they provide the opportunity for a face-toface encounter.

\subsection{Re-integrative shame theory of restorative practices}

Nathanson's shame theory considers shame and its effects on individuals. He identifies a compass of shame that includes withdrawal, avoidance, attacks on the self, and attacks on others. These points of the shame compass represent a kind of continuum of responses to events that are shameful to the individual (who can be a victim or an offender). If we consider their connection to infiltrated virtual communities with little or no regulatory influence, we can begin to consider how the victim of the cyberbully is exponentially shamed in the process of one negative posting which instantly can become multiple follow-up postings in the cyber world. The compass of shame also includes those who do the bullying as they, too, through discovery may be revealed [as cited in 24].

In an effort to understand why most people do the right thing most of the time, Braithwaite [4] considers the idea of re-integrative shaming (in community) as opposed to disintegrative shaming (which occurs when members are ostracised). Through affective questions, restorative questions, and small and large group conferencing, it is theorized that this encounter and questions are intended to elicit affect and, in the process, establish empathy. For the cyber victims, this may afford the opportunity to freely express their feelings about the incident(s). For the cyberbully or aggressor, this may afford her/him the opportunity to regain some empathy that was lost in an online exchange.

\subsection{Emerging theory}

If restorative practices present the opportunity to increase affect through face-to-face encounters, and if re-integrative shame allows for responsibility-taking and maintaining positive relationships in school communities, then restorative practices can be considered as a means of increasing or clarifying social presence lost in the online environments that adolescents frequent, which are typically outside of the regulatory influences of parents and peers in faceto-face encounters. This sequence of events is presented as Figure 3: Schools as nexus for cyber events.

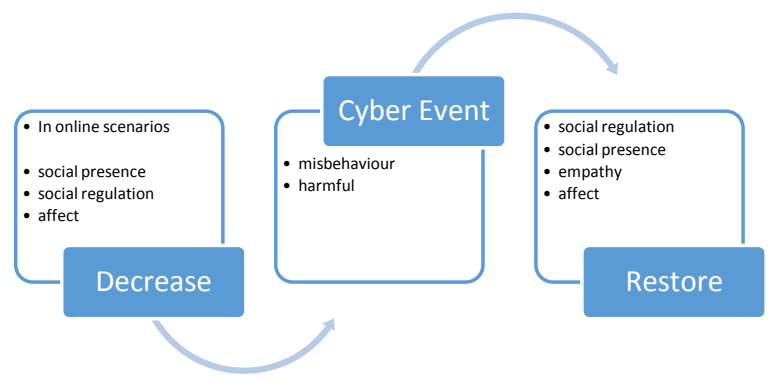

Figure 3. Schools as nexus for cyber events (Corrigan \& Robertson, 2015)

School administration is perceived to be key in establishing a safe school culture. From monitoring and documenting cyber activity through data collections, to policy responses, to school culture involvement, to parent engagement, schools are considered to be the nexus, situated to respond to bullying and online aggression.

\section{Methods}

This study uses mixed-methods research, primarily qualitative, to examine how nine secondary school vice-principals in three different school districts respond to harmful cyber events. The research employs a NING, a private online discussion community where the vice-principals can share their insights with each other and with the researcher. Through weekly postings, questions based on Wachtel's social discipline continuum [24] were asked of school leaders. They responded online with the ability to comment on each other's responses. 
All of the vice principals' responses were collected in a qualitative database and analyzed for recurring themes. The resulting findings provide a window on how vice-principals both theorize and operationalize their conceptions of restorative practices. Based on these findings, the authors propose that the theoretical underpinnings do support school leaders' efforts to build community pre and post cyber-events.

Earlier approaches to school discipline in Ontario, as seen through a review of the literature, were perceived as punitive, so much so that they were brought to the attention of the Ontario Human Rights Commission. Safe School policies in Ontario were subsequently revised and, in the process, they offered alternative approaches to school disciplinary responses. These changes now allow the school administrators to choose from a toolkit of potential responses related to legislated expectations. The research outlined here explored the basis on which school leaders were making decisions about which tools they would use when responding to cyber events.

This study also examined current secondary school administrators' views regarding the efficacy of restorative practices as a means of responding to cyberbullying and online aggression. It also examined how and in what circumstances secondary school administrators use restorative practices for incidents that happen or originate online.

\section{Findings}

The findings from this study provide a window into what is happening in the contributing secondary schools with respect to restorative practices and cyber events. First of all, a finding which was not expected was that most of the school leaders in the study observe what is happening in social media, and use social media to track student behaviour, but they participate rarely, if at all, in social media for their own personal purposes, preferring to look in at the online world from the edges.

Other findings were more predictable. The study was designed to assess school leaders' training in restorative practices. These findings are reported in the section which follows. The second and third categories of findings focus on the use of restorative practices. The school leaders reported both proactive restorative practice use as well as restorative practices which were responsive to the cyber events. The fourth category of findings indicates that the vice principals in this study use restorative practices as learning opportunities. These findings are categorized in this way and reported below.

\subsection{Vice principal training}

All vice principals in the study indicated that they possessed an understanding of restorative practices. Approximately $1 / 3$ of the vice principals had workshop training. 1/3 had one-day training, and approximately $1 / 3$ had two-day training. Most respondents, therefore, had some degree of training in restorative practices but not extensive training. It was evident from the study's findings that, regardless of the level of training, the vice-principals included restorative practices as part of their toolkit for maintaining a respectful community in their schools.

\subsection{Proactive restorative practices}

One of the interesting findings of this study is that, while some respondents indicated that no negative cyber events were reported, they still felt that restorative practices were being used that focused on the proactive communication approaches the school had to prevent cyberbullying. One respondent posted that "Prevention/awareness is a big factor for us and having students repair harm and learn from their mistakes is very important." Proactive approaches included offering workshops to attempt to prevent incidents and to help create a healthy school climate in an effort to proactively "make things right." Members of the community were also brought in to address students in assemblies in an "attempt to prevent incidents and to help create a healthy school climate." This language, included in the restorative questions asked in conferences and encounters, would appear to be part of the language administrators used in their statements to students as a general approach to students involved in schoolbased and online conflicts.

This idea of prevention and awareness as part of restorative practice is reflective of earlier claims that restorative practices can precede the harmful incident in a proactive way [24].

\subsection{Responsive restorative practices}

Most of the events reported by vice principals taking place over the six-week research period were in response to cyber events that had created harm to other students. The reporting of the events was not always done by the victims of the cyber issues. School leaders reported that all stakeholders in schools - staff, parents, and students- were potential sources of information for negative online behaviour and cyberbullying.

The continuum of responsive restorative practices reported in this study ranges from informal to formal 
interventions which administrators may choose to use in response to cyber wrongdoing.

The research data did indicate that small impromptu conferences were held. Vice principals did acknowledge the use of affective questions in their dealings with both students who had been wronged and students who had caused harm. The participants appeared to use these questions in different circumstances with different degrees of formality. For example, one responded stated "we generally tend to fluctuate from the informal affective statements to the small impromptu conferences and/or group conferences." Another vice principal indicated that they used a small impromptu "offenders only" conference. They did not articulate the nature of the questions nor the extent to which they had been adapted.

However, the vice principals did not always use small conferences. They did not, during the course of this study, identify using a large group conference. They did, however, consider using it but this decision was subject to the willingness of those involved in the cyber incident.

Sometimes a "restorative focus" was reportedly used with one vice principal responding that establishing dignity, putting aside grievances, and maintaining respect were the outcomes of schoolbased restorative practices.

In one instance reported by a vice-principal, restorative practices were used to respond to tweets made in relation to a school-based verbal altercation. In this case, the altercation preceded the tweets, but the tweets preceded the restorative practices.

Restorative practices were also used in the early stages of an investigation of online threats although this practice, too, was in response to cyber aggression. In this case, however, the instigator was not interested in participating in a restorative conference.

Restorative practices were also used in relation to a team conflict that had then escalated on social media. In this case, small and individual conferences with restorative questions took place. The schoolbased conflict preceded the negative cyber activity which was met with restorative practices.

Restorative practices were also considered in response to threatening online behaviour by someone who was impersonating a student. This example was especially complex and was followed by a number of sanctions that included police involvement. Once again, a vice-principal reported that restorative practices were used in response to negative cyber activity.

\subsection{Adaptation by the vice principals}

Vice principals reported variations in how they considered and used restorative practices in relation to online aggression and cyberbullying. For example, they took action at different points of the restorative continuum. Sometimes that included only asking restorative questions. Sometimes that included impromptu conferences although the data indicated that school administrators rarely used the formal conferences. The findings indicated that while vice principals typically decided upon what kind of restorative practice was used, that decision was subject to the willingness of students to participate as they "must be open to discussion." In other words, vice-principals used discretion to determine the level of formality of the restorative conference.

Vice principals also reported the consideration of time. In short, circumstances, willingness, and time were identified as considerations in the use of restorative practices as found in the restorative continuum. As one vice principal stated, "We can't always restore relationships... What we can do is come to a common understanding."

While vice principals fitted restorative practice responses to the nature of the cyber event, they cited instances in which they would not proceed with restorative practices. For example, both parties have to agree to voluntarily participate. The offender has to agree to participate and take responsibility. As one vice principal stated, "A restoration meeting will only move forward in a positive direction if both parties are willing to be open to discussion."

Vice principals also reported using other resources and sanctions that included police, social work, ongoing parent communication, and what they identified as ongoing restorative practices as a result of the complexity of the cyber issue.

\section{Conclusions}

This study finds that while the vice principals in this study were not, themselves, involved in social media, they found themselves working at the edge of social media because schools are indeed at the nexus or the point where out-of-school, online behaviour becomes reported to the school because it has impacted students and the school community. The vice-principals also reported that their schools were experiencing a range of different situations associated with online misconduct of a harmful nature but that most of the incidents did not involve bullying. The vice-principals indicated that the restoration of community and safety was something they took very seriously and occupied a fair amount of their time. 
This study finds that vice principals consider the use of both formal and informal approaches, and apply discretion to determine the level of formality matching a definition of restorative practices which is "the use of informal and formal processes that precede wrongdoing... build relationships and a sense of community to prevent conflict and wrongdoing" [24]. In addition, the school administrators report that they use both proactive and preventative approaches. Most of the restorative practices reported by the vice principals were in response to a negative cyber events or a school event that had spilled over into social media which also was met with a restorative response.

\subsection{Informal use}

With respect to the restorative practices continuum (Figure 1), this study finds that the vice principals generally use situational restorative practices and most often, informally. They described their use of restorative practices as in fluctuation and in relation to individual situations. They reported their use of restorative practices as using statements, questions, and small impromptu conferences in response to wrongdoing.

The findings in this study would indicate that vice principals adapt restorative practices to suit the circumstances of the situation. They also readily opted not to include some participants if they were not willing or if their participation would further affect the victim. This is in keeping with the established principles of restorative practices as articulated by Wachtel [24]. Of interest in this study's findings is that no formal conferences were reported during the six weeks of data collection.

If violations against people and relationship create a sense of responsibility which then becomes the obligation to make things right [25], then the vice principals who participated in this study appear to understand and enact these principles and, in the process have assumed this responsibility themselves. For example, the vice principals in this study used Zehr's specific language of "making things right." They also spoke repeatedly of a sense of obligation they had to "keep students safe", an obligation they said that preceded the legislation requiring them to do so.

McCluskey et al., [15, 16] make a critical distinction as they consider approaches used by schools that include restorative practices and those found exclusively in the legal system. In the legal system, the victim and the offender do not have to continue to be part of the same community. In schools, those involved in the conflict often do remain in the community.. This study supports this finding. Because of this distinction, what happens in schools requires a distinct skill and experience set. All restorative approaches and practices in schools are subject to the ongoing interaction of both victims and offenders in classrooms, in social media sites, and in anonymous chatrooms. The vice principals in this study indicated that restorative practices in schools require the willingness of both parties to make this happen but also the awareness that "We can't always restore relationships."

The vice principals in this study also discussed the importance of educating parties about the nature of communication online. They want students to understand that online activities establish a "digital footprint" which is an online record of the harmful event unfolding. The vice principals attempted to at least soften the digital footprint if they could and they wanted students to use cyber events as learning experiences.

\subsection{Recommendations}

Restorative practices, as indicated by the responses of the Ontario secondary school vice principals in this study, are seen as one viable means of responding to negative online activity including conflict and cyberbullying. Although these online environments typically indicate a lack of social regulation through social presence, these deficiencies can be offset by the use of restorative practices. This offers some encouragement to continue to train school leaders in restorative practices while still acknowledging that they will use discretion in their application.

According to the data provided, vice-principals report that their responses may be proactive, preventative measures or actions taken in response to a harmful cyber event. Regardless, school leaders report that they create opportunities for students to take responsibility and to feel empathy. The responses of the vice-principals indicate that it seems promising that online activity can be regulated through attempts to maximize affect, create opportunities for empathy, and taking responsibility. These findings may help other school leaders to see both the proactive and responsive uses for restorative practices. In addition, it is hoped that this study helps other secondary school vice principals see themselves and the situations that they encounter reflected in this research.

Further, this study also provides recognition that the schools have become the nexus for cyber crisis management and restorative practices solutions. Given that reality, there is also promise seen in the potential of restorative practices as a productive response to the reported rise in cyberbullying and 
online conflict. Academics, school stakeholders, policy writers, and lawmakers who view this research may be encouraged to continue research into social presence and the impact of its absence in the anonymity of social media.

\subsection{Limitations and implications for further research}

This is a small study which took place over a sixweek data collection period. Further reporting on this study will consider both the policy context of secondary schools and the absence of social presence in harmful cyber events. More research is needed to understand as well, why the secondary school administrators in this study report that they use social media only from the sidelines or "standing on the edge" of their students" cyber-worlds.

\section{References}

[1] Ahmed, E., \& Braithwaite, J. (2005). Forgiveness, shaming, shame and bullying. Australian \& New Zealand Journal of Criminology, 38(3), 298-323.

[2] Aragon, S.R. "Creating Social Presence in Online Environments", New Directions for Adult and Continuing Education, 2003 (100), 57-68.

[3] Boulton, J. \& Mirsky, L. "Restorative Practices as a Tool for Organizational Change", Reclaiming Children and Youth: The Journal of Strength-Based Interventions, 2006, 15(2), 89-91.

[4] Braithwaite, J. (1989). Crime, shame and reintegration. Cambridge University Press.

[5] Calhoun, A. \& Daniels, G. "Accountability in School Responses to Harmful Incidents", Journal of School Violence,2008,7(4),21-47,doi: $10.1080 / 15388220801973839$.

[6] Cassidy, W., Faucher, C. \& Jackson, M. Cyberbullying among youth: A comprehensive review of current international research and its implications and application to policy and practice. School Psychology International, 2013 34(6), 575-612.

[7] Fong, P. Victim of cyberbullying commits suicide, October 12, 2012, Retrieved from

thestar.com:http://www.thestar.com/news/caada/article/127

0262-b-c-victim-of-cyberbullying-commits-suicide

[8] Government of Ontario. (2000). Safe schools act. Bill 81, Chapter 12. Statutes of Ontario.

[9] Grossi, P.K. \& dos Santos, A.M. "Bullying in Brazilian Schools and Restorative Practices", Canadian Journal of
Education/Revue canadienne de l'education, 2012, 35(1), 120-136.

[10] Hasenstab, J.J. "Cyberbullying: A Study of School Administrators' Perceptions and Responses to Online Aggression ," 2012, (Doctoral dissertation, SAINT LOUIS UNIVERSITY).

[11] Köbler, F., Riedl, C., Vetter, C., Leimeister, J. M., \& Krcmar, H. (2010). Social Connectedness on Facebook-An explorative study on status message usage.

[12 Legislative Assembly of Ontario. (2012, June). Bill 13, Accepting schools act, 2012. Retrieved from Legislative Assembly of Ontario:http://ontla.on.ca/web/

bills/bills_detail.do?locale $=$ en $\&$ BillID $=2549$

[13] Macready, T. (2009). Learning social responsibility in schools: a restorative practice. Educational Psychology in Practice, 25(3), 211-220.

[14] Mark, L. \& Ratliffe, K.T. Cyber Worlds: New Playgrounds For Bullying. Computers in the Schools, 2011 28(2), 92-116.

[15] McCluskey, G., Lloyd, G., Kane, J., Riddell, S., Stead, J., \& Weedon, E. (2008a). Can restorative practices in Schools make a difference? Educational Review, 60(4), 405-417.

[16] McCluskey, G., Lloyd, G., Stead, J., Kane, J., Riddell, S., \& Weedon, E. (2008b). 'I was dead restorative today': From restorative justice to restorative approaches in school. Cambridge Journal of Education, 38(2), 199-216.

[17] McCold, P., \& Wachtel, T. (2001). Restorative justice in everyday life. In H. Strang \& J. Braithwaite (Eds.) Restorative justice and civil society, 114-129, New York: Cambridge University Press.

[18]Morrison, B., \& Ahmed, E. (2006). Restorative justice and civil society: Emerging practice, theory, and evidence. Journal of Social Issues, 62(2), 209-215.

[19] Ontario Human Rights Commission. (2004). Submission of the Ontario Human Rights Commission to the Toronto District School Board Safe and Compassionate Schools Task Force.

[20] Rettie, R. Connectedness, Awareness And Social Presence, 2003.

[21] Tomkins, S.S. Affect, Imagery, Consciousness: Vol. I. The Positive Affects. 1962, Oxford: Springer.

[22]Team, S. S. A. (2006). Safe schools policy and practice: An agenda for action. Toronto: Ontario Ministry of Education.

[23]Uhls, Y. T., Michikyan, M., Morris, J., Garcia, D., Small, G. W., Zgourou, E., \& Greenfield, P. M. (2014). Five days at outdoor education camp without screens 
International Journal of Digital Society (IJDS), Volume 6, Issue 3, September 2015

improves preteen skills with nonverbal emotion cues.

Computers in Human Behavior, 39, 387-392.

[24] Wachtel, T. Defining Restorative, 2013, Retrieved from www.iirp.edu/pdf/Defining-Restorative.pdf

[25] Zehr, H. The Little Book of Restorative Justice 2002

(Vol. 266). Intercourse, PA: Good books. 